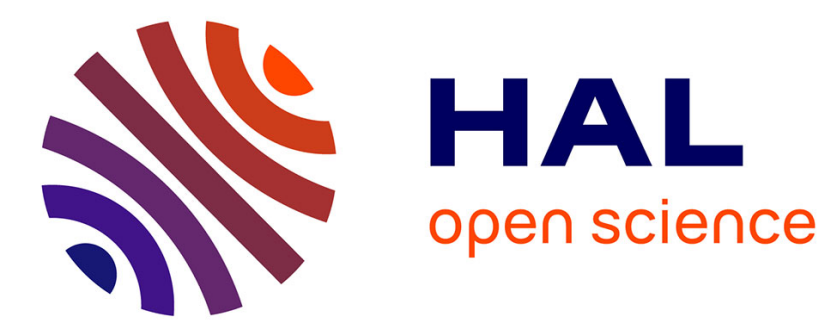

\title{
Non equivalent optical centres in Pr3+ doped LiNbO3
}

\author{
A. Lorenzo, L. Bausá, M. Voda, J. García-Solé
}

\section{To cite this version:}

A. Lorenzo, L. Bausá, M. Voda, J. García-Solé. Non equivalent optical centres in Pr3+ doped LiNbO3. Journal de Physique IV Proceedings, 1994, 04 (C4), pp.C4-381-C4-384. 10.1051/jp4:1994491 . jpa00252754

\section{HAL Id: jpa-00252754 https://hal.science/jpa-00252754}

Submitted on 1 Jan 1994

HAL is a multi-disciplinary open access archive for the deposit and dissemination of scientific research documents, whether they are published or not. The documents may come from teaching and research institutions in France or abroad, or from public or private research centers.
L'archive ouverte pluridisciplinaire HAL, est destinée au dépôt et à la diffusion de documents scientifiques de niveau recherche, publiés ou non, émanant des établissements d'enseignement et de recherche français ou étrangers, des laboratoires publics ou privés. 


\title{
Non equivalent optical centres in $\mathrm{Pr}^{3+}$ doped $\mathrm{LiNbO}_{3}$
}

\author{
A. LORENZO, L.E. BAUSÁ, M. VODA ${ }^{(1)}$ and J. GARCÍA-SOLÉ \\ Departamento de Física de Materiales C-IV, Universidad Autónoma de Madrid, Cantoblanco, \\ 28049 Madrid, Spain
}

\section{INTRODUCTION}

In recent years, $\mathrm{LiNbO}_{3}$ has become a very interesting material for laser applications in integrated optics. Doping with a small concentration of rare-earth ions permits the design of lasers with a number of interesting features such as self-frequency doubling, self-Q-switching or self-mode locking [1]. For a well characterization of the material, it is necesary to know the different impurity centres as well as the possibilities of controlling the relative distribution of these centres. The different optically active centres can be detected and characterized by absorption and fluorescence experiments [2].

In this work, the presence of non-equivalent $\mathrm{Pr}^{3+}$ ions in the LiNbO crystal host has been detected by optical methods. In this sense, the ${ }^{4} \mathrm{H}_{3} \rightarrow{ }^{3} \mathrm{P}_{0} \quad$ transition was investigated using polarized absorption measurements at low temperature (10K). The influence of both concentration and stoichiometry on the relative distribution of $\mathrm{Pr}^{3+}$ ions in different non-equivalent centres is analyzed.

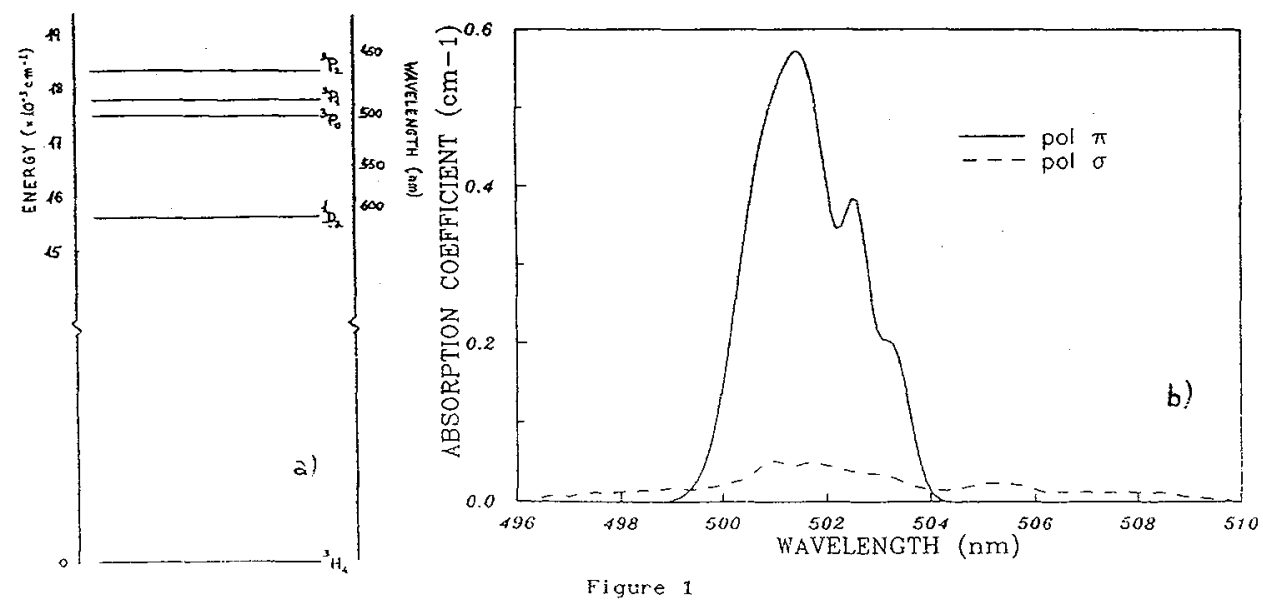

- (1) On leave from Institute of Physics and Technology of Materials, Bucharest-Magurele, P.O. Box MG7, Romania 


\section{EXPER IMENTAL}

Crystals were grown by Czrochalski method in our laboratory with different stoichiometries in the melt: [Li]/[Nb] $=0.94$ (congruent), 1 (stoichiometric) and 0.88 . For these experiments, the concentration of $\operatorname{Pr}^{3+}$ ions in the melt was the same for the three crystals: 0.2 mol\%. Other values $(0.5 \%$ and $1 \%)$ were also used in congruent crystals to investigate the effect of concentration.

\section{RESULTS ANS DISCUSSION}

Figure la shows a simplified energy level diagram including the states of $\mathrm{Pr}^{3+}$ ion in $\mathrm{LiNbO}_{3}$ in the visible range. This diagram was obtained by taking the gravity centre of each multiplet from our low temperature absorption spectra. In Figure 1b, polarized absorption spectra for the ${ }^{3} \mathrm{H}_{4} \longrightarrow{ }^{3} \mathrm{P}_{0}$ transition can be seen. The ${ }^{3} \mathrm{P}_{0}$ excited multiplet is unsplit due to its $J=0$ number, so it has $A$ symmetry character, thus it is a good level to study the presence of multisites. As can be seen that transition is $\sigma$-polarized $(E \perp c)$ and the same spectrum is observed for $\alpha$ polarization (beam $\perp$ c). Thus, it can beconcluded that this is a forced electric dipole transition. Since the $\pi$ spectrum (E $\|$ c) is flat $(\pi$-polarized transition is forbiden) the $E$ symmetry character of the ground sublevel of ${ }^{3} \mathrm{H}_{4}$ multiplet can be inferred [3].

A fourfold structure for the ${ }^{3} \mathrm{P}_{0}$ multiplet is observed. This structure could be related to different centres of $\mathrm{Pr}^{3+}$ ions in $\mathrm{LiNbO}_{3}$, all of them Figure 2

with the same symmetry character. To corroborate the proposed "site structure, laser site selective spectroscopy was performed under excitation within the ${ }^{3} \mathrm{H}_{4} \longrightarrow{ }^{3} \mathrm{P}_{0}$ transition. From the ${ }^{3} \mathrm{P}$ level, non-radiative relaxation ocurrs to ${ }^{1} \mathrm{D}_{2}$ and from this multiplet, luminescence ocurrs. Results are shown in Figure 2 where different ${ }^{1} \mathrm{D}_{2} \longrightarrow{ }_{4}^{3} \mathrm{H}_{4}$ fluorescence 
spectra are depicted for a different excitation wavelengths absorption band. Splitting of the ${ }^{3} \mathrm{H}_{4}$ multiplet can be, in principle, obtained from these spectra for each $\operatorname{Pr}^{3+}$ site.

From the absorption spectum it is clear that the four bands are very close in energy and strongly overlapping. Thus, even with a narrow-line laser, more than one site are being excited at the same time, giving place to very complex spectra in which emissions from different centres overlap. Anyway, by scanning the excitation wavelength through the absorption band some changes can be observed. The magnitude of the ${ }^{3} \mathrm{H}_{4}$ splitting is not the same for all excitation wavelengths and the positions of the peaks change as well. This effects allow us to confirm the existence of, at least, four non-equivalent centres for $\mathrm{Pr}^{3+}$ in $\mathrm{LiNbO}_{3}$.

On the other hand, ${ }^{3} \mathrm{P}_{0}$ polarized absorption spectra for different stoichiometries are shown in Figure 3. It can be seen that both, the relative intensity and the width of each site, change with the [Li]/[Nb] ratio. This behavior indicates that the incorporation of $\mathrm{Pr}^{3+}$ ions to each site is dependent on the defects associated to the non-stoichiometry of the host. In fact, it was proposed that the excess of $\mathrm{Nb}$ ions produces the existence of $\mathrm{Nb}$ ions located in $\mathrm{Li}$ regular lattice sites; (called antisites positions) and in this situation charge compensation was achieved with Nb-vacancies [4]. Impurity ions are supposed to incorporate the matrix in these defects. Since the amount of defects Figure 3 in a crystal is directly related to the inhomogeneous broadening, then the narrowing of absorption bands indicates less defects and a greater degree of crystalline order. This is in agreement with our results since absorption bands in stoichiometric $\mathrm{LiNbO}_{3}: \mathrm{Pr}^{3+}$ are the narrowest ones, thus confirming the better ordering in the stoichiometric melt. 
Finally, the dependence of absorption spectra with concentration of $\mathrm{Pr}^{3+}$ is being studied. Two samples of congruent $\mathrm{LiNbO}_{3}$ with $0.5 \mathrm{~mol}^{3}$ and 1 mol\% of $\mathrm{Pr}^{3+}$ in the melt were grown and oriented to make polarized absorption experiments. In Figure 4, $\sigma$-polarized ${ }^{3} \mathrm{H}_{4} \rightarrow{ }^{3} \mathrm{P}$ transition of $\mathrm{LiNbO}_{3}: \mathrm{Pr}^{3+}(0.5 \mathrm{~mol} \%)$ is displayed. The greater value for the absorption coefficient indicates a higher incorporation of $\mathrm{Pr}^{3+}$ ions into the crystal host. The same shape is observed with a fourfold structure similar to that of $\mathrm{LiNbO}_{3}: \mathrm{Pr}^{3+}(0.2 \mathrm{~mol} \%)$. But, on the other hand, a very broad band appears at higher enegies and increases with concentration. This new band which is still increased in the 1 mol\% doped crystal, could be due to the presence of $\mathrm{Pr}$ clusters. In fact, the appearance of these clusters is directly observed as dispersive spots by looking at the sample. Additional experiments are being carried out to characterized these new Pr centres.

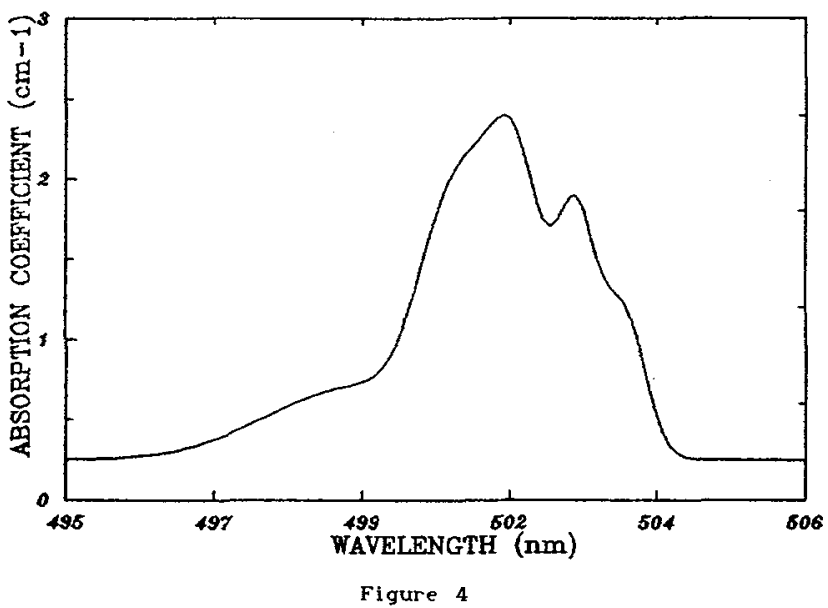

\section{REFERENCES}

[1]. E.Lallier, J.P.Pocholle, M.Papuchon, M. de Micheli, M.J.Li, Q.He, D. B. Ostrowsky, C.Grezes-Besset And E.Pelletier. Optics Letters 15, 682 (1990).

[2]. J.Garcia-Solé, B. Macalik, L. E. Bausá, F. Cussó, E. Camarillo, A.Lorenzo, L. Nuñez, F. Jaque, A.Monteil, G.Boulon, J.E. Muñoz Santiuste and I. Vergara, J. Electrochem. Soc. 140, 2010 (1993).

[3]. B.Henderson and J.P. Imbusch. "Optical Spectroscopy of Inorganic Solids", Oxford Science Publications, Clarendon Press, Oxford (1989).

14]. S. C.Abrahams and P.Marsh, Acta Crystallogr. B 42, 61 (1986). 